\title{
Treatment of Chronic Paronychia: A Double Blind Comparative Clinical Trial Using Singly Vaseline, Nystatin and Fucidic Acid Ointment
}

\author{
Khalifa E. Sharquie ${ }^{1 \#}$, Adil A. Noaimi², Sunbul A. Galib ${ }^{3}$ \\ ${ }^{1}$ Scientific Council of Dermatology \& Venereology, Iraqi Board for Medical Specializations, Department of Dermatology \& \\ Venereology, College of Medicine, University of Baghdad, Baghdad, Iraq; ${ }^{2}$ Department of Dermatology \& Venereology, College of \\ Medicine, University of Baghdad, Baghdad, Iraq; ${ }^{3}$ Department of Dermatology \& Venereology, Baghdad Teaching Hospital, Bagh- \\ dad, Iraq. \\ Email: " ksharquie@ymail.com
}

Received September $12^{\text {th }}, 2013$; revised October $10^{\text {th }}, 2013$; accepted October $18^{\text {th }}, 2013$

Copyright (C) 2013 Khalifa E. Sharquie et al. This is an open access article distributed under the Creative Commons Attribution License, which permits unrestricted use, distribution, and reproduction in any medium, provided the original work is properly cited.

\begin{abstract}
Background: Chronic paronychia is a chronic inflammatory reaction of the proximal and lateral nail folds of multifactorial in etiology like irritant, bacterial and monilial causes. But housewife work is a major cause of chronic paronychia. Objective: To assess the efficacy and prophylactic effects of Vaseline by occlusion of nail folds in comparison with nystatin ointment and fucidic acid in treatment of housewife chronic paronychia. Patients and Methods: This double, blinded, comparative therapeutic, clinical trial is conducted at the Department of Dermatology-Baghdad Teaching Hospital from May 2010 to May 2011. Eighty female housewife patients with chronic paronychia were included in this trial. They were divided into three groups according to the following therapeutic model: Group A treated by Vaseline consisted of 40 patients; Group B and Group $\boldsymbol{C}$ treated by nystatin ointment, fucidic acid ointment respectively and each group consisted of 20 patients. All demographic points related to the disease were recorded from all patients. Invented score system was applied to assess the severity of disease and the response to therapy. Patients had used therapy twice daily on the proximal and lateral nail folds. Treatment duration was 12 weeks. Results: Group A (Vaseline): The recovery rate after 12 weeks of treatment was $26(65 \%)$ patients, while there was no recovery in $14(35 \%)$ patients. Group $\boldsymbol{B}$ (Nystatin ointment): The recovery rate after 12 weeks was $13(65 \%)$ cases and there was no recovery in $7(35 \%)$ patients. Group C (Fucidic acid ointment): The recovery rate 12 weeks of treatment was $12(60 \%)$ patients and there was no recovery in $8(40 \%)$ patients. The earliest signs of recovery in all groups were decreased in nail fold tenderness, redness, swelling followed by improvement in the nail shape, then decreased in the separation of proximal nail fold from nail bed followed by re-growth of cuticle. There was significant difference in clinical response before and after therapy in all groups $(\mathrm{P} \leq 0.0001)$ while there was no statistical significant difference when the three groups were compared with each other $(\mathrm{P}=0.784)$. Conclusions: Vaseline occlusion therapy of the nail folds in patient with chronic paronychia was enough to induce recovery from the disease and there was no statistical significant difference when compared with nystatin or fucidic acid treatment of chronic paronychia.
\end{abstract}

Keywords: Housewife; Paronychia; Vaseline; Occlusive Therapy

\section{Introduction}

Chronic paronychia is a major health problem of which housewife paronychia is the main type seen in daily clinical practice [1].

The etiopathogenesis is multifactorial, but the wet con-

${ }^{*}$ Disclosure: This study is an independent study and not funded by any drug company.

${ }^{\#}$ Corresponding author. dition during housewife work will cause loss of nail cuticle followed by separation of proximal and lateral nail folds and this will make a dead space thus allowing the entrance of water, detergents, bacteria under the nail folds followed by inflammation leading to the main features of chronic paronychia mainly swelling of the nail folds, nail dystrophy; this is so-called wet theory [2].

Accordingly, the presence of candida and bacteria like 
Staph aureus, alpha, beta and gamma-haemolytic Streptococci, Klebsiella pneumonia, Bacteroides species and Coliform, Pseudomnas aeruginosa, Proteus species and other organisms as Diphtheroids, Streptococcus fecalis, and Staphphylococcus albus are considered as secondary invader in the pathogenesis of chronic paronchia [3]. Hence, the aim of therapy is to close the so-called dead space and encourage the adhesion of nail cuticle and nail folds thus preventing the entrance of water, detergents and bacteria. Therefore, the management of chronic paronychia should start by prevention of wet conditions and giving antimicrobial agents to stop the process of inflammation, but unfortunately, many practicing dermatologists give antifungal, antibacterial drugs for long time aiming to enhance cure but without stopping the wet conditions, so recurrence is always high [2].

Still many housewives do not take the advice of wearing gloves and again will prevent healing of chronic paronychia [4].

Accordingly, the aim of present work is to do occlusion of the dead space by Vaseline alone compared with using antimicrobial agents like fucidic acid and nystatin and to record the therapeutic response to these therapies.

\section{Patients and Methods}

This double blind comparative therapeutic trial on the effectiveness of two drugs topically applied on the nail folds (nystatin and fucidic acid) compared with Vaseline on treatment of housewife chronic paronychia. This was conducted in the Department of Dermatology and Venereology-Baghdad Teaching Hospital, Baghdad, Iraq from May 2010-May 2011.

Eighty female patients with house wife chronic paronychia were enrolled in this study. Inclusion criteria included all patients with housewife chronic paronychia who attended for therapy. The diagnosis of chronic paronychia was established according to the following criteria: housewife patients, absence of cuticle associated with swelling and erythema of proximal and lateral nail folds, separation of dorsal and lateral nail folds from nail plate. While, exclusion criteria as follow: acute paronychia, infections like tinea unguam, warts, and herpetic whitlow. Also, dermatological diseases that can cause chronic paronychia such as pemphigus vulgaris, psoriasis, and lichen planus, connective tissue diseases like systemic lupus erythematosus, discoid lupus erythematosus, dermatomyositis, and scleroderma were excluded. Peripheral vascular disease like perniosis, Burger's disease, Raynaud's disease, patients with immunosuppressive conditions, bone deformities, diabetes mellitus, and conditions requiring systemic or topical use of corticosteroids, calcineurin inhibitors, retinoids and pro- tease inhibitors were not included.

A full history was taken from each patient regarding name, age, gender, marital status, residence, social status, job, number of children, using of gloves and washing machine, right or left hand, baking, smoking. Also duration, number of fingers involved, and type of treatment used before.

All patients were examined regarding right or left hand involvement or both, number of nails involved, presence of swelling, tenderness, and purulent discharge, presence of nail changes as buckled nail plates, transverse ridging, nail discoloration and associated onycholysis or dystrophy.

Formal consent was taken from each patient before starting the trial of treatment after full explanation of nature of disease, course, prognosis, complications, nature of drug, method of application, duration of treatment and follow up and the ethical approval was obtained from Scientific Council of Dermatology and Venereology, Iraqi Board for Medical Specializations.

Evaluation of the patients was done to re-evaluate the disease score and report any side effects from treatment clinically and by photograph during study period of 12 weeks.

All patients were photographed by a digital camera as a baseline and then on 12 weeks, in the same place with fixed illumination and distance by using a digital camera (Sony: Cyber shoot with resolution 12 mega pixels).

The following scoring system of the chronic paronychia was invented:

1) Loss of cuticle score $=1$

2) Separation of proximal nail fold from nail bed with different grades and this was measured by orange stick introduced under the nail folds:

a. Separation just score $=1$

b. Separation $2 \mathrm{~mm}$ score $=2$

c. Separation $>2 \mathrm{~mm}$ score $=3$

3) Swollen nail fold:

a. Swollen just score $=1$

b. Swollen red score $=2$

c. Swollen tender score $=3$

4) Secondary nail changes:

a. Ridging score $=1$

b. Dystrophy score $=3$

When patients had multiple fingers involvement, the severely affected one was scored only and the others although treated they were not counted within scoring.

The treatment protocol: Patients were divided into 3 groups:

Group A: using topical white petrolatum $\left(\right.$ Vaseline $^{\circledR}$ ) manufactured by Anglo-Dutch Company Unilever.

Group B: using topical nystatin ointment in Vaseline base $\left(\right.$ Mycodin $\left.^{\circledR}\right)$ is manufactured by The State Company 
for Drug Industries and Medical Appliances NinavahaIraq, under license of SDI Co.15 grams tube. Each gram contains nystatin 100.000 I.U of the ointment.

Group C: using topical fucidic acid ointment in Vaseline base (Fusibact ${ }^{\mathrm{TM}}$ ) manufactured by Jamjoom Pharma. 15 grams tube.

Each 100 gram of the ointment contains the active substance sodium fusidate, which corresponds to 2 gram sodium fusidate.

The treatment was applied twice daily on the proximal and lateral nail folds. Treatment duration was 12 weeks. All patients were advised to avoid cuticle trimming, nail biting, picking, trauma and also were encouraged to use rubber gloves with inner cotton lining for household tasks.

Statistical analysis was carried out using paired t-test to compare differences before and after treatment in each group. Chi-square test was used to check relations between results either recovery or no recovery. $P$ value less than 0.05 was considered significant. SPSS (statistical package for social sciences) version 17 was used for the analysis.

\section{Results}

Eighty housewife patients with chronic paronychia were completed the study their ages ranged from 15 - 68 with mean \pm SD of $37.26 \pm 11.06$ years. The role of contributing factors showed that moisture; super hydration, detergents and rough work played the highest role in damaging the nail cuticle and nail folds in all patients. Duration of disease ranged from half year- 12 years with mean \pm SD of $2.166 \pm 2.66$ years. Total numbers of 184 fingers involved in 3 groups. Number of finger involved ranged from $(1-8)$ with mean \pm SD of $2 \pm 9.61$ fingers. The nail changes in patients of chronic paronychia demonstrated in (Table 1).
Patients in Group A were treated by White petrolatum ointment; forty house wife patients were included in this group, their ages ranged from $15-60$ years with mean \pm SD of $36.37 \pm 10.8$ years. Married females were 32 $(80 \%)$ patients. They had $(0-8)$ children with mean of 4 children. Twenty seven (67.5\%) patients were using washing machine, while only $3(7.5 \%)$ patients were using gloves. Twenty (50\%) patients were baking regularly. All of them were right handed $40(100 \%)$. Duration of disease ranged from less than 1 year - 12 years with mean \pm SD of $2.6 \pm 3.44$ years. Total number of 88 fingers was involved.

Right hand alone was involved in 29 (72.5\%), while both right and left hands were involved in 11 (27.5\%). Number of finger involved ranged from $(1-7)$ with mean \pm SD of $2 \pm 1.55$ finger. Seventeen (42.5\%) patients with 1 finger involvement, 8 (20\%) patients with 2 fingers, $8(20 \%)$ patients with 3 fingers, $4(10 \%)$ patients with 4 fingers, $3(7.5 \%)$ patients with 6 fingers. No any side effect reported from treatment. Most commonly involved finger in right hand was middle finger $22(55 \%)$ followed by thumb 19 (47.5\%), ring finger $18(45 \%)$, index $13(32.5 \%)$ with no little finger involvement. While in left hand most common finger involved was thumb $7(17.5 \%)$, both middle and ring fingers $4(10 \%)$ and index only $1(2.5 \%)$.

Patients in Group B were treated by nystatin ointment; twenty house wife patients were included in this group, their ages ranged from 19-55 years with mean \pm SD of $37.40 \pm 10.75$ years. Married females were $18(90 \%)$ patients. They had $(0-7)$ children with a mean of 3 children. Twelve $(60 \%)$ patients were using washing machine. Three $(15 \%)$ patients were using gloves. Ten $(50 \%)$ patients were baking regularly.

All of them were right handed $20(100 \%)$. Duration of disease ranged from less than 1 year - 12 years with

Table 1. The nail changes in patients of chronic paronychia at presentation.

\begin{tabular}{|c|c|c|c|c|c|c|}
\hline & \multicolumn{2}{|c|}{ Group A (Vaseline) } & \multicolumn{2}{|c|}{ Group B (Nystatin ointment) } & \multicolumn{2}{|c|}{ Group C (Fucidic acid ointment) } \\
\hline & No. & $\%$ & No. & $\%$ & No. & $\%$ \\
\hline Loss of cuticle & 40 & 100 & 20 & 100 & 20 & 100 \\
\hline Nail fold swelling & 40 & 100 & 20 & 100 & 20 & 100 \\
\hline Separation of nail fold from nail plate & 40 & 100 & 20 & 100 & 20 & 100 \\
\hline Transverse ridging & 39 & 95 & 20 & 100 & 20 & 100 \\
\hline Longitudinal ridging & 8 & 20 & 2 & 10 & 2 & 10 \\
\hline Nail pitting & 28 & 70 & 13 & 65 & 10 & 50 \\
\hline Onycholysis & 8 & 20 & 1 & 5 & 2 & 10 \\
\hline Nail plate dystrophy & 5 & 12.5 & 3 & 15 & 2 & 10 \\
\hline Color changes & 34 & 85 & 17 & 85 & 15 & 75 \\
\hline
\end{tabular}


mean \pm SD of $1.98 \pm 2.74$ years. Total number of 39 fingers was involved. Number of finger involved ranged from $(1-8)$ with mean of \pm SD of $2 \pm 1.71$ fingers, thirteen $(65 \%)$ patients with 1 finger involvement, $2(10 \%)$ patients with 2 fingers, 3 (15\%) patients with 3 fingers, 1 (5\%) patient with 4 fingers, $1(5 \%)$ patient with 8 fingers. No any side effect reported from treatment. Right hand alone was involved in $13(65 \%)$, left hand was involved in $2(5 \%)$, while both right and left hands were involved in $5(25 \%)$. Most commonly involved finger in right hand was thumb $11(55 \%)$ followed by ring finger 7 (35\%), middle finger $5(25 \%)$, index $4(20 \%)$, little finger only $1(5 \%)$, while in left hand most common finger involved was middle $4(20 \%)$, followed by index 3 $(15 \%)$, then both ring and thumb $2(10 \%)$ for each one while little finger was not involved.

Patients in Group $\boldsymbol{C}$ were treated by fucidic acid ointment; twenty house wife patients were included in this group, their ages ranged from $22-68$ years with mean \pm SD of $38.90 \pm 12.195$ years. Married females were 19 $(95 \%)$ patients; they had $(0-8)$ children with a mean of 4 children.

Eleven (55\%) patients were using washing machine. One $(5 \%)$ patient was using gloves. Nine $(45 \%)$ patients were baking regularly. All of them were right handed 20 (100\%). Duration of disease ranged from less than 1 year - 10 years with mean \pm SD of $2.035 \pm 2.178$ years. Total number of 57 fingers was involved.

Number of finger involved ranged from $(1-6)$ with mean of $\pm \mathrm{SD}$ of $3 \pm 1.576$ fingers, four $(20 \%)$ patients with 1 finger involvement, 7 (35\%) patients with 2 fingers, $3(15 \%)$ patients with 3 fingers, $3(15 \%)$ patients with 4 fingers, 1 (5\%) patient with 5 fingers, $2(10 \%)$ patients with 6 fingers. No any side effect reported from treatment. Right hand alone was involved in $12(60 \%)$, while both right and left hands were involved in $8(40 \%)$. Most commonly involved finger in right hand was thumb $16(80 \%)$ followed by index and middle fingers $10(50 \%)$ for each finger, then ring finger $5(25 \%)$, little finger only $1(5 \%)$, while in left hand most common finger involved was thumb $6(30 \%)$, followed by index $4(20 \%)$, then middle $3(15 \%)$ lastly ring finger was $2(10 \%)$.

\section{Clinical Response}

According to the present study results we can divide patients in each group into: patients with recovery and patient without recovery.

1. Recovery: either cured: re-growth of cuticle, no separation of nail folds from nail bed, normal proximal nail fold, nail plate grows normally or improved: absence of cuticle, nail folds just separated from nail bed, normal proximal nail fold, nail plate grows nor- mally (score $=0$ - 2).

2. No recovery: either stable: absence of cuticle, nail folds separated from nail bed $>2 \mathrm{~mm}$, proximal nail folds just swollen, abnormal nail plate (ridging, dystrophy) or worse: absence of cuticle, nail fold separated from nail bed $>2 \mathrm{~mm}$, proximal nail fold swollen tender, abnormal nail plate (ridging, dystrophy) with purulent inflammation of the proximal nail fold ( score $=3-11)$.

There were highly statistically significant differences in recovery of paronychia in all groups when we compared the scoring before and after therapy after 3 months of treatment $(\mathrm{P} \leq 0000.1)$ (Table 2 and Figure 1).

When the three groups where compared between each other, there was no significant statically difference in recovery rate between them $(\mathrm{P}=0.784)$ (Table 3$)$.

\section{Discussion}

Chronic paronychia is an inflammatory dermatosis of the nail folds, with secondary effects on the nail matrix; nail growth and soft-tissue attachments [5].

The etiology of chronic paronychia is multifactorial in origin [6]. Infection by multipule organism, especiallyyeasts (commonly Candida albicans) and intestinal bac-

Table 2. The recovery of chronic paronychia patients before and after therapy in the 3 groups.

\begin{tabular}{ccccccc}
\hline Group & & $\begin{array}{c}\text { Range } \\
\text { of score }\end{array}$ & $\begin{array}{c}\text { Mean } \\
\text { of score }\end{array}$ & $\begin{array}{c}\text { St. } \\
\text { dev. }\end{array}$ & t-test & P-value \\
\hline A & Before & $7-11$ & 8.10 & 1.150 & & \\
Vaseline & After & $0-11$ & 3.65 & 2.627 & & \\
B & Before & $5-11$ & 7.85 & 1.348 & & \\
Nystatin & After & $0-10$ & 3.60 & 2.945 & 6.514 & $<0.0001$ \\
C & Before & $6-11$ & 8.15 & 1.348 & & \\
Fucidin & After & $0-8$ & 3.70 & 2.452 & & \\
\hline
\end{tabular}

Table 3. The clinical response to treatments in the $\mathbf{3}$ groups.

\begin{tabular}{ccccccc}
\hline \multicolumn{7}{c}{ Group } \\
\hline & $\begin{array}{c}\text { Group A } \\
\text { (Vaseline) }\end{array}$ & $\begin{array}{c}\text { Group B } \\
\text { (Nystatin) }\end{array}$ & \multicolumn{2}{c}{$\begin{array}{c}\text { Group C } \\
\text { (Fucidin) }\end{array}$} \\
\hline & No. & $\%$ & No. & $\%$ & No. & $\%$ \\
\hline Recovery rate & 26 & 65 & 13 & 65 & 12 & 60 \\
No recovery rate & 14 & 35 & 7 & 35 & 8 & 40 \\
Total & 40 & 100 & 20 & 100 & 20 & 100 \\
& Value & & Df & \multicolumn{2}{c}{ P value } \\
Chi-Square $\left(\mathrm{x}^{2}\right)$ & 0.487 & & 2 & & 0.784 \\
\hline
\end{tabular}




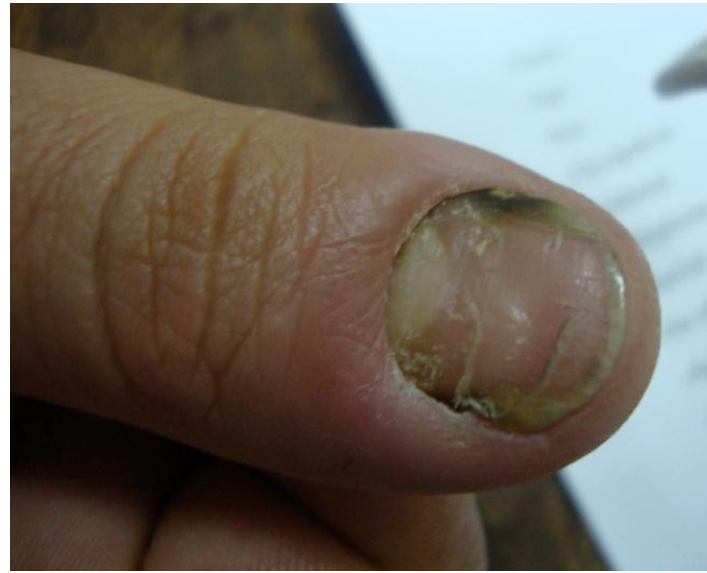

(a)

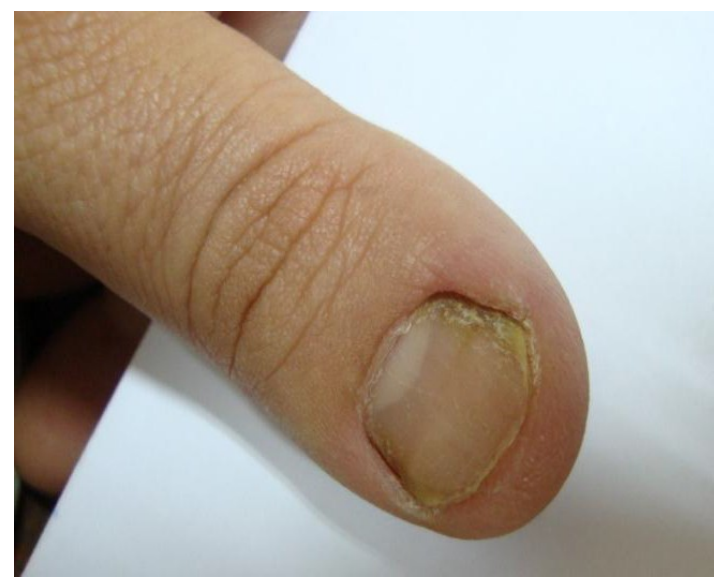

(b)

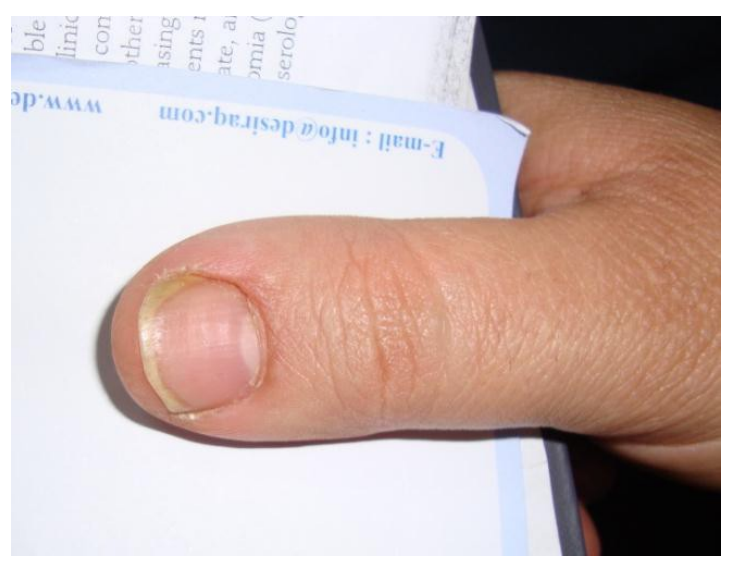

(c)

Figure 1. Chronic paronychia in the right thumb in a housewife before and after treatment by topical Vaseline. (a) At presentation; (b) At 6 weeks after treatment; (c) At 12 weeks after treatment.

teria, is proposed to be a major etiologic factor, but recent studies have established the pivotal role of irritants and allergens in the development of chronic paronychia [7].
Chronic paronychia is a major health problem among Iraqi house wife dermatoses as it accounts for $33.3 \%$ of the whole occupational housewife dermatoses [2].

It is well established that house wife work is the main etiological factor in the etiopathogenesis of chronic paronychia where it works through the following factors: the wet condition and the trauma of house work will cause loss of nail cuticle followed by separation of proximal and lateral nail folds this will allow water, detergents, bacteria to enter under the nail folds followed inflammation leading to the main features of chronic paronychia mainly swelling of the nail folds, nail dystrophy, this is so called wet theory [2].

Sharquie et al. performed a study in 1990 on microbiology of chronic paronychia in Iraqi housewives. [2] The primary isolation from cultures on Sabouraud's agar showed Candida organisms in $93.3 \%$ of the cases, of which $88.3 \%$ were Candida albicans, while the bacterial isolates were mainly: Coliform in $33.3 \%$, Pseudomnas aeruginosa plus coliform in $26.6 \%$, Proteus species plus coliforms in $8.3 \%$, Staphylococcus aureus $16.6 \%$, and other organisms as Diphtheroids, Streptococcus fecalis, and Staphphylococcus albus [2]. And these findings were supported by further studies [8].

But presence of these bacteria and candida might play secondary role in the pathogenesis of paronychia [2]. So, the therapy of chronic paronychia is mainly through prevention of house work through wearing gloves. Still many dermatologists use antibacterial and antifungal therapy for long time to treat chronic paronychia but in most of cases there is a failure of treatment [2]. So, the aim of present work is the treatment of paronychia just through using any ointment like Vaseline to block the entrance of detergents and bacteria under the nail folds and to the dead space under these folds. And this treatment was compared with topical antifungal and antimicrobial agents.

The results of present study showed that using Vaseline, nystatin or fucidic acid where highly statistically significant effective in clearing paronychia $(\mathrm{P} \leq 0.0001)$, when these groups where compared with each other there was no statistically difference $(\mathrm{P}=0.784)$.

The group that used Vaseline showed the following results: recovery rate was $26(65 \%)$ patients, while there was no recovery in $14(35 \%)$ patients, while patients in nystatin group showed recovery rate in $13(65 \%)$ patients, while there was no recovery in 7 (35\%) patients. While, patients on fucidic acid ointment gave recovery rate in $12(60 \%)$ patients, while there was no recovery in $8(40 \%)$ patients. Accordingly, the present study had proved that occlusion of nail folds from wetting condition through using Vaseline or antimonilial ointment or antibacterial ointment was enough to clear signs and 
symptoms of paronychia and even might prevent the relapse of the disease through ointment. The present research to the best of our knowledge is the first one that has been carried out in the field of chronic paronychia.

\section{Conclusion}

In conclusion, treatment of paronychia by occlusive therapy using Vaseline alone is enough to induce recovery and clearance of housewife paronychia.

\section{REFERENCES}

[1] K. E. Sharquie and S. I. Al-Omran, "Occupational Housewife Dermatosis," Diploma Dissertation, University of Baghdad, Baghdad, 1988.

[2] K. E. Sharquie, S. M. Al-Salloum and R. N. Al-Saadi, "Microbiology of Chronic Paronychia in Iraqi Housewives," Journal of Pan Arab League of Dermatologists, Vol. 1, No. 2, 1990, pp. 17-23.

[3] I. Brook, "Paronychia: A Mixed Infection: Microbiology and Management," The Journal of Hand Surgery: Journal of the British Society for Surgery of the Hand, Vol. 18,
No. 3, 1993, pp. 385-359.

[4] C. R. Daniel, M. P. Daniel, C. M. Daniel, S. Sullivans and G. Ellis, "Chronic Paronychia and Onycholysis: A Thirteen Year Experience," Cutis, Vol. 85, No. 6, 1996, pp. 397-401.

[5] D. A. R. De Berker and E. R. Baran, "Disorders of Nails," In: T. Burns, S. Breathnach, N. Cox and C. Griffiths, Eds., Rooks Textbook of Dermatology, 6th Edition, Blackwell Scientific Publications, Melblorne, 1998, p. 65.

[6] C. Grover, B. S. N. Reddy and K. U. Chaturvedi, "Nail Biopsy: An Assessment of Indications and Outcome," Dermatologic Surgery, Vol. 31, No. 2, 2005, pp. 190-194. http://dx.doi.org/10.1111/j.1524-4725.2005.31042

[7] E. S. M. Wong, R. J. Hay, Y. M. Clayton and W. C. Noble, "Comparison of the Therapeutic Effect of Ketoconazole Tablets and Econazole Lotion in the Treatment of Chronic Paronychia," Clinical and Experimental Dermatology, Vol. 9, No. 5, 1984, pp. 489-496. http://dx.doi.org/10.1111/j.1365-2230.1984.tb00843.x

[8] M. A. A. Al-Nuaimi, "Chronic Paronychia: The Fungal and Bacteriological Etiology in Iraqi Patients," MS Thesis, University of Baghdad, Baghdad, 2001. 